\title{
Energy Storage and Electric Vehicles: Technology, Operation, Challenges, and Cost-Benefit Analysis
}

\author{
Surender Reddy Salkuti \\ Department of Railroad and Electrical Engineering, Woosong University, Daejeon, Republic of Korea
}

\begin{abstract}
With ever-increasing oil prices and concerns for the natural environment, there is a fast-growing interest in electric vehicles (EVs) and renewable energy resources (RERs), and they play an important role in a gradual transition. However, energy storage is the weak point of EVs that delays their progress. The world's EV industry is accelerating to faster adoption with appropriate incentives to the EV owners, policy support, and encouraging local manufacturing. The increasing demand for EV's has presented itself as an authentic alternative to internal combustion engines (ICE). The main feature of the RERs is their variability and intermittency. These drawbacks are overcome by integrating more than one renewable energy source including backup sources and storage systems. This paper presents various technologies, operations, challenges, and costbenefit analysis of energy storage systems and EVs.
\end{abstract}

Keywords-Energy storage; electric vehicles; cost-benefit analysis; demand-side management; renewable energy; smart grid

\section{INTRODUCTION}

The demand for the electrical energy is increasing in the modern world; however the fossil fuel-based energy systems are polluting and depleting existing the available reserves. Environmental awareness is worldwide increasing. New paradigms are emerging, like electric vehicles (EVs), smart grids, electrical markets, and vehicle-to-grid (V2G). The novel grid techniques are demonstrated for the optimal integrated operation of RERs and EVs to increase the penetration of renewable energy. The need for conservation of fast-depleting natural resources and concerns about environmental protection are demanding for sustainable green energy technologies [1, 2]. Nowadays, the focus on alternative renewable energy is increased and the predominant RERs are wind power, solar PV power, and hydro power. The amount of power availability from these RERs follows some daily and seasonal patterns, but the power demand by the consumers follows different characteristics. Solar PV generation is omnipresent, low operational cost, less maintenance, it can be easily accommodated in roof-tops and eco-friendly energy conversion processes. The integration of RERs makes the system more complex concerning the power-sharing, control, and analysis [3].

The international energy roadmap study ranks solar PV, biomass, windmills, and tidal power as future sources of renewable energy to sustain the world's economy. Progress in the field of sustainable energy scenario over the previous span of time has been exceptional. The two main sustainable energy resources are the sun and the wind [4]. The growth in electricity generation from renewable was substantially increased. Toward the finish of 2016, the world's aggregate wind power generation remained at $486.8 \mathrm{GW}$. 2016 has seen near to $75 \mathrm{GW}$ of extra introduced PV capacity around the world, a stunning 50\% over 2015 and raising the aggregate newly introduced capacity to around $300 \mathrm{GW}$ [5]. As in 2016, China, USA and Japan displayed the biggest markets representing seventy-five percent of the extra introduced capacity in these three nations alone [6, 7]. In the interim, 66\% of the worldwide PV limit is being introduced in the AsiaPacific locale with China in front of all others over $34 \mathrm{GW}$ of installed limit in 2016. 24 nations have now achieved total installed limits over $1 \mathrm{GW}, 16$ nations introduced no less than 500 MW amid 2016 and in no less than 27 nations, PV contributes with $1 \%$ or more to the yearly power supply. In 2017, PV will add to around 2\% of the world's power generation [8, 9]. The IEA ventures by 2050, around (15-18) $\%$ of worldwide power is going to be created from the wind with sun-powered PV contributing as high as $16 \%[10,11]$ regardless of its different favorable circumstances.

With the integration of RERs such as wind and solar, significant uncertainty into the power system is developed. It is a great challenge for system operators to maintain reliable operation and efficient electricity markets with simultaneous maximum utilization of renewable energy. As the electric market structures change to improve the management of renewable sources, advances in the design and pricing aspects of energy and ancillary services markets are needed. The main objectives of an energy management system are to ensure the maximum utilization of RERs, continuous power supply to the load, reduce the cost of energy production and increase the stability of the system [12]. To achieve these objectives efficiently and fast control techniques are required which are capable of processing information intelligently and taking critical decisions dynamically within the operational constraints.

EVs are propelled by electric motors and use the electrical energy stored in the batteries. EVs are required to reduce the dependence on fossil fuel and to reduce pollution as transportation accounts for one-third of all energy usage. By using the EVs $100 \%$, the $\mathrm{CO}_{2}$ emission can be reduced by half. EVs save energy, less pollution, and noise, cheaper to run and maintain. However, they also include some challenges such as selecting the battery size and its capacity, locations of charging stations, faster charging, speed and mileage of the vehicle, and its efficiency. Various components of EVs include electronic controllers, energy storage systems, power electronic converters, and electric motors [13]. Various EV technologies include battery EVs (BEVs), hybrid EVs (HEVs), plug-in HEVs (PHEVs), and fuel cell EVs (FCEVs). 
The author in [14] reviews the recent trends and directions of optimal control strategies of ESSs. The author in [15] presents the potential profit by using the second-life batteries from the EVs. A comparison between various integration approaches of EVs subjected to the availability of PV systems and superconducting magnetic ESSs has been presented in [16]. The author in [17] describes the energy management benchmarks and sizing guides of battery-supercapacitor hybrid ESSs in EV applications. The author in [18] presents different EV distributed renewable energy coordination approaches by considering the costs and the associated infrastructure. Analysis of energy storage tanks and the types of accumulators used for EVs and the patterns of the Li-ion battery is presented in [19]. The author in [20] presents the estimation of supercapacitor storage influence on Li-ion battery cycle life and EV performance. An overview of various technologies of ESSs, their characteristics, constructions, classifications, evaluation, and electricity conversion processes with advantages and disadvantages for EV applications has been presented in [21].

The integration of renewable sources such as wind and solar introduce significant uncertainty into the power system. It is a great challenge for system operators to reliable operation and efficient electricity markets with simultaneous maximum utilization of renewable energy. As the electric market structures change to improve the management of renewable sources, advances in the design and pricing aspects of energy and ancillary services markets are needed. In this paper, the integration of storage devices including the existing storage technologies such as pumped hydro as well as utilityscale battery systems collocated with solar and wind farms are considered. Due to the high capital cost of the energy storage systems, a study is performed considering the trade-off between the economic costs and reliability for different levels of penetration of these systems. The main objective of this work is to determine suitable ways to combine some forms of energy storage systems (ESSs) such as flywheel with lithiumion batteries to achieve load balancing in the smart grid.

The remaining work of this paper is prepared as follows: Section II presents the description of various energy storage systems. Different electric vehicles are described in Section III. Section IV presents the cost-benefit analysis. Conclusions are summarized in Section V.

\section{ENERGY STORAGE SYSTEMS (ESS)}

RERs are unpredictable and there is a gap between the availability and usage of these resources. There is always a difference between the production and consumption of such resources. As a result, it is of immense importance to build storage units that can preserve the energy and make it available for later use. In the present scenario, certain storage technologies include compressed air, supercapacitors, and advanced battery systems. Proper utilization of RERs will enable the protection and longevity of the environment by reducing pollution. They ensure continuity of energy supply and improve the reliability of the system by providing excellent energy management techniques. Energy storage systems can be in many forms and sizes. Energy can be stored as potential, kinetic, chemical, electromagnetic, thermal, etc.
[22, 23]. Some energy storage forms are better suited for small-scale systems as well as for large-scale storage systems. Some of the energy storage systems are chemical batteries, fuel cells, ultra-capacitors or supercapacitors, superconducting magnetic energy storage, and flywheels, etc. The potential applications of energy storage systems include utility, commercial and industrial, off-grid, and microgrid systems. Renewables with energy storage can act as the baseload power source of a microgrid and reduce the use of fossil-fuel-based generators [24]. Energy storage is the conversion of unused energy at any given time into a form that can be stored for use at a later time. The issue of energy storage arises with the need to match the demand and supply of energy to individuals. The advent of electricity brought about more concern for the need for energy storage due to its prior nature of being used up when generated or converted to another form of energy [25]. However, new trends in energy show ways these generated energies could be stored and harnessed.

\section{A. Battery Energy Storage}

A battery is an electrochemical device that stores electrical charges through chemical reactions. There are two types of batteries, primary (disposable) and secondary (rechargeable). A primary battery converts the chemical reactions into electricity only once. Batteries used for large-scale ESSs are secondary/rechargeable batteries. The charging and discharging of a battery is a reduction-oxidation process. During the discharge, electrons are transferred from the battery to the load through the process of oxidation [26]. When charging, electrons are transferred to the battery when a voltage is applied to its terminals. This is referred to as a reduction process.

Various battery energy storage technologies used for EVs include Lithium-ion, Lead-acid, Nickel-metal hydride, and Sodium nickel chloride. The first three batteries operate at room temperature whereas the last one operates at $300^{\circ} \mathrm{C}$. A lithium-ion battery is a leader among battery storage technology for EVs. Sodium nickel chloride is a low maintenance battery with limited use as it is going to operate at $300^{\circ} \mathrm{C}$. Battery-operated EVs have low initial infrastructure cost, low noise, high efficiency, low operational cost, and zero emissions [27]. Major challenges involved with battery technology are charge time, cost, shelf life, specific power, cycle life, specific energy, safety, ease of manufacture, and recyclability. Energy sources provide electrical energy onboard the EV. The types of energy storage technologies that have been proven to be viable and improvement have been going in are batteries (electrochemical cells), fuel cells, ultracapacitors, and flywheel storage. In the foreseeable future, batteries are still the major source of energy for EVs. Newer types of batteries like metal-air, flow batteries, sodium-ion batteries, Sulphur based batteries, etc. [28]. The end goal is to achieve the same range as when gasoline is used in EVs. The battery energy storage system can be modeled as [29],

$$
\begin{aligned}
& S_{t+1}=S_{t}(1-\varepsilon)+\left[P_{D C}(t)+\eta_{R} P_{A C}(t)-P_{D}(t)\right] \eta_{C B} \\
& S_{t+1}=S_{t}(1-\varepsilon)-\left(\frac{\eta_{I} P_{A C}(t)-P_{D}(t)}{\eta_{D B}}\right)
\end{aligned}
$$

Where $S_{t+1}$ is state of charge of battery at time $(\mathrm{t}+1), \varepsilon$ is hourly self-discharge rate, $P_{A C}(t)$ is $\mathrm{AC}$ power generation at 
time t, $P_{D C}(t)$ is DC power generation at time t, $P_{D}(t)$ is load demand at time t, $\eta_{R}$ is the efficiency of rectifier system [30], $\eta_{C B}$ is the charging efficiency of the battery, $\eta_{D B}$ is the discharging efficiency of the battery, and $\eta_{I}$ is the efficiency of the inverter system.

\section{B. Lithium-ion (Li-ion) Batteries}

Li-ion batteries are quite inexpensive, high energy, power densities, and highly efficient. This battery is composed of a negative electrode (carbon), a positive electrode (metal oxide), and an electrolyte (Lithium salt). These batteries do not pose a huge environmental impact. However, they tend to explode when exposed to high temperatures or short-circuited [31]. Flywheels are one of the oldest means of storing energy. It is a mechanical storage device that is used in storing rotational energy. They have a moment of inertia and resist the changes in rotational speed. It absorbs energy and acts as a reservoir. Torque is applied to a flywheel to transfer energy. Unlike flywheels, batteries are a slow chemical process that is subject to the recharge or discharge process [32]. Like all electrical devices, batteries can only recharge slowly regardless of the available input energy. Most flywheels are built to where they rarely wear out. The cost of batteries compared to flywheel storage is must cheaper.

\section{Supercapacitors or Ultra-capacitors}

These are the electromechanical capacitors that have usually high energy density when compared to common capacitors. For the same size as in conventional capacitors, the supercapacitors will have a capacitance of several farads, an improvement of about two or three orders of magnitude in capacitance, but usually at a lower working voltage, and hence they have very high energy densities [33]. It is having advantages over other technologies like a very high rate of charge and discharge, high output power, high efficiency, etc. Practical implementations of supercapacitors involve connecting various cells in parallel strings to maximize the storage capacity.

As the development of technology has merged towards EVs, the supercapacitors with high energy density are used for fast charging, and temperature stability. These supercapacitors are also used in flash photography devices, media players, automated meter reading. Supercapacitors have high efficiency (up to 95\%), however, future research can be performed in terms of dielectric materials and other components by reducing the energy per unit weight. The charging rate of capacitors is limited by the current heating of an electrode. The layers in an electrical double layer are conductive when it is seen by itself, however, when they keep contacting, then no current flow occurs. When supercapacitors are compared to the batteries, their energy density is about one-tenth of the battery. However, when it comes to power density, the supercapacitors have a higher rate which is about 10 to 100 times better than the battery [34]. The electrical double layer occurs when the two plates with the same condition are being separated and it leads to the separation of charges even though their separation possibility is very rare. The double-layer only can accelerate the low voltage but if it needs the higher voltage to be used, and then make the capacitors connected in serious [35]. Various types of batteries for EVs and their specifications are presented in Table I.

\section{Demand Side Management (DSM)}

The conventional power grid is being replaced by a smarter grid through the implementation of several innovative changes such as demand response (DR) programs, distributed energy resources (DERs), and DSM. DSM is required because saving 1 unit of electricity at the consumer end avoids nearly 2.5 times of energy capacity addition. DSM leads to use less energy during peak hours, i.e., peak clipping and shifting the energy to use it in off-peak hours, i.e., valley filling. Therefore, DSM can help in meeting the demand at a lower cost. The DSM strategies include peak clipping, valley filling, load shifting, strategic conservation, strategic load growth, and flexible load shape [36]. The benefits of DSM reduce the peak load demand, reduces the cost of operation, minimizes the power import from the utility grid, and maximizes the use of RERs. Vehicle-to-grid (V2G) technology enables the energy to be pushed back to the power grid from the battery of an EV to help supply energy at the time of peak load demand. These EVs can provide a strong option with no extra cost. DSM acts as an energy-efficient measure that modifies/reduces the end user's energy demand, and it leads to cost reduction, environmental and social impact, reliability and network issues, and improved markets.

DSM provides energy efficiency options for the effective demand of customers and enabling them to cut their expenses by cost optimization. DSM also helps in the reduction of emissions and hence enables a more sustainable power system. It lowers the cost of transmission and also contributes to the reliability of generation. It obligates energy providers to main proper power levels and constant frequency levels. Moreover, with the advent of PV generation, DSM needs to be optimized further to enable it to handle fluctuation in power supply and system frequency, which may affect the operation of consumer appliances. In addition to that, optimal DSM technologies should also be developed for distributors and storage equipment.

TABLE I. VARIOUS TYPES OF BATTERIES FOR EVS AND THEIR SPECIFICATIONS

\begin{tabular}{|l|l|l|l|l|}
\hline Name of the battery & Specific energy $\mathbf{( W h / k g )}$ & Specific Power $\mathbf{( W / k g )}$ & Number of life cycles & Cost $\mathbf{( \$ / k W h )}$ \\
\hline Valve regulated lead acid & $30-45$ & $200-300$ & $400-600$ & 150 \\
\hline Nickel Cadmium & $40-60$ & $150-350$ & $600-1200$ & 300 \\
\hline Nickel Metal Hydride & $60-120$ & $150-400$ & $600-1200$ & $200-350$ \\
\hline Zinc-air & 230 & 105 & N/A & $90-120$ \\
\hline Sodium-Sulphur & 100 & 200 & 800 & $250-450$ \\
\hline Lithium-ion & $90-160$ & $250-450$ & $1200-2000$ & $600-1000$ \\
\hline
\end{tabular}




\section{ELECTRIC VeHICLES (EVS)}

An EV is a mode of transport that is partly or completely propelled using electricity as its energy source. EVs were invented 178 years ago. The first EV was a battery-powered tricycle built by Thomas Davenport in 1834. EVs eventually lost the competition for dominance to combustion engines. Interests in EVs rekindled in the 1970s due to the outbreak of the energy crisis and oil shortage. The developmental pace of EVs accelerated when there was growing concern over air quality and the greenhouse effect in the 1980s. To achieve the desired level of performance, the ESSs (i.e., batteries) inside the vehicle need to have a very high capacity and efficiency to be able to give the vehicle enough power to drive. The development of more improved batteries currently plays a huge role in the design of EVs.

Apart from technological advancement, access to charging infrastructure plays a vital role in scaling up EV's. EV operation from the grid perspective includes load regulation with voltage and current constraints, maximize operational efficiency, and for EV aggregators perspective it manages the ancillary services, charging fairness, and minimizing the battery degradation. From the EV cost aspects, the objective of the problem includes the minimization of cost of power operations and EV charging costs and the maximization of grid operator revenue and aggregator profit. Various research problems that need to be addressed related to EVs are the demand response, selection of EV charging station, distribution system operation, frequency regulation by EV benefits maximization of profit of parking lot owner and vehicular energy network, etc. [37]. From the grid point of view, the challenges in EVs include infrastructure, power quality, and intermittency as EV is an intermittent load and includes large penetration of RERs and grid operators to maintain grid stability. For the analysis of EVs, the data required includes the energy supply data, demand data, road network data, power network data, forecast data, load curve with and without EVs, and the time of day prices.

\section{A. Classification of EVs}

EVs are mainly classified based on their energy sources and the propulsion devices as battery electric vehicles (BEVs), hybrid electric vehicles (HEVs), fuel cell electric vehicles (FCEVs), and plug-in hybrid EVs (PHEVs). A hybrid EV has two or more power sources and there are a large number of possible variations. These hybrid EVs combine an internal combustion engine (ICE) with a better and electric motor and generator. These hybrid EVs are maybe in series hybrid or parallel hybrid.

\section{B. Battery Electric Vehicles (BEVs)}

The BEVs are generally termed EVs, rely on using batteries as their sole or major source of the energy storage device to store electricity. They have minimum overall emissions and zero tailpipe emissions. At the present status of battery technology, the energy storage capacity of BEVs is far less than that of internal combustion engine vehicles (ICEVs). Therefore they have a problem of range anxiety and also, BEV's are more expensive than general ICEVs. There is also the factor of charging time, for the batteries which depends on the previous state of charge of the batteries and their size [38]. But due to the recent introduction of fast charging methods and/or battery swapping, the charging time problem can be solved.

\section{Hybrid Electric Vehicles (HEVs)}

HEVs implement an ICE combined with an electric motor, where the participation of the electric motor in the net power produced decides the HEV grade (micro, mild and full). HEVs have improved fuel economy, lesser environmental impact than their ICEV counterparts, and longer range too. But these vehicles become costlier due to their extra inventory.

\section{Fuel Cell Electric Vehicles (FCEVs)}

These vehicles also offer zero-tailpipe emissions and minimum overall emissions. Besides, the driving range in these vehicles is comparable to that of an ICEV. Its major challenges are the lacking technology to produce safe fuel cells, and they have a very high initial cost. There is also a lack of hydrogen refueling infrastructure, which would take a huge investment cost to set up. The commercialization and mass production of FCEVs in the future will depend on whether there will be a technological breakthrough in fuel cell technology.

\section{E. Plug-in Hybrid EVs (PHEVs)}

In PHEVs, the storage batteries are charged from regenerative braking energy, external charging, and by an engine connected through the generator, however, the amount of energy received from regenerative braking is very less. Therefore, for the driving mode of operation of $\mathrm{EV}$, an engine connected through a generator is used [39]. They are designed to extend the range of an EV without compromising the performance, and therefore the cost is high.

\section{F. Motor Drive EV Technology}

Motor drives convert the on-board electrical energy to the desired mechanical motion. The motor drive technology for EVs is being rapidly improved in recent years, due to the developments in the design, analysis, and control of motor drives. Electric machines are the key elements of motor drive technology. The performance requirements of electric machines for EVs are much more demanding than those for industrial applications. The requirements of the electric motors include high torque and power density, wide constant power operating capability, high reliability and robustness, high efficiency over wide torque and speed ranges, high torque capability to compensate acceleration variations (start and climbing), cost efficiency, and low acoustic noise and losses.

EV machines are classified into commutator and commutator-less machines. The latter doesn't have a commutator or brushes. Motors like DC motors, permanent magnet DC (PMDC) motor, cage rotor induction motors, permanent magnet brushless (AC and DC), and switched reluctance motors (SRMs) have been widely applied to EVs. There is also a trend of developing new types of doubly salient configurations for EV motors like the doubly salient permanent magnet (DSPM) [36]. The advantages of using brushless DC (BLDC) motors include low maintenance, 90+\% efficiency, high operating speeds, no brush sparking, and 
compact size, quick response, less rotor inertia, predictable speed regulation, quieter operation, and regenerative braking with good efficiency. As one can notice, the benefits of using BLDC motors are higher especially from its brushed counterparts and induction motors, making it more suitable for EV applications.

\section{G. Challenges and Issues of EVs}

Various challenges and issues associated with EVs are: EVs should be available at a competitive price when compared with internal combustion engines (ICE), the efficiency of EV's should be more at high speed and high load, quality of vehicles, safety and security features during usage. Other challenges include the import of battery manufacturing consists of lithium, nickel, cobalt, aluminum, and graphite, dependency and price volatile may impact EVs' total cost, the impact of EV charging stations on the grid, which create huge demand for electric power and may cause additional burden and unscheduled load demands, providing reliable charging infrastructure and determining the cost of charging, availability of land in densely populated urban localities for charging stations, and dynamic, predictable and encouraging government policies are needed for creating a necessary ecosystem of EVs.

\section{Cost-Benefit ANALysis (CBA)}

The cost-benefit strategy/analysis for quantifying the impact of RERs penetration with the consideration of PV/optimum tracking problem of renewable energy mix and control signals to the network performance has been presented in this paper. Ranking of controls would be done to compute the impacts in maintaining secure and reliable power management and the development of integrated schemes for real-time power management with RERs [32]. The unit commitment (UC) problem is an electrical generation unit scheduling problem. The aim is to determine a schedule over a time horizon that satisfies forecasted demand and technical requirements. Historically integer programming and other optimization approaches have been used to solve the UC problem. Additional challenges for solving the UC include the integration and optimization of very high, variable RERs and flexible consumer demand. Stochastic and robust optimization techniques seek to address the significant variability in the problem. To develop the criteria for affordability, reliability constraints, and economic benefits; the computation of pricebased uncertainties must be developed by using advanced optimization schemes with foresight and flexibility. The CBA of penetration of RERs into RER integrated system in terms of impact on network performance must be evaluated and computed.

World's energy roadmap study ranks PV, biomass, windmills, and tidal power as future sources of renewable energy to sustain the world's economy. Traditional studies on RERs integration have focused on power quality improvement using one or two RERs, and on their impacts on grid performance. The components that made up the RERs integrated systems and RERs would be energy storage, load control, and advanced power electronics, which interface between the RERs and the grid provider. The electricity demand is rarely constrained over time. This task involves the review of conventional and innovative storage methodologies for incorporation and optimal use of the RERs energy outputs. A study on modeling and performance of both conventional storage methodologies (i.e. batteries), innovative storage (i.e. flywheels) methodologies, associated power electronics for conversion and control, and an introduction of storage technologies to an integrated environment for simulation and experimentation will be useful for understanding this analysis [38]. For this, the capability of optimized and integrated renewable energy management systems using real-time measurements and local control is required. Depending on the power system an engineer desires to build, the CBA can help select a storage option. For example, if discharge duration was the highest on an engineers' priority list, then choosing the storage technique that allows getting the maximum benefit (discharge duration) for the given budget would be the selection.

\section{CONCLUSIONS}

This paper presents the need for electric vehicles (EVs) and various critical aspects that are instrumental in making EVs a sustainable, reliable, and affordable option for future mobility. Due to the intermittent nature of renewable energy resources (RERs), it is of utmost importance to store the excess energy when available and can be used for periods of excess load or inefficient supply. Due to the growing awareness of the harmful impact of conventional fossil fuels and advancements in renewable energy technologies, energy storage and EVs have grown in popularity. In this work, conventional and innovative storage techniques such as batteries, supercapacitors, and EVs are reviewed along with their merits, limitations, and performance. This paper also presents the cost-benefit analysis which is helpful to make a good engineering decision. Having strong numerical evidence based on cost is a great way to invest.

\section{ACKNOWLEDGMENT}

This research work was funded by "Woosong University's Academic Research Funding - 2021”.

REFERENCES

[1] S. Sharma, A.K. Panwar, M.M. Tripathi. Storage technologies for electric vehicles, Journal of Traffic and Transportation Engineering, vol. 7, no. 3, pp. 340-361, Jun. 2020.

[2] X. Wu, X. Hu, X. Yin, S.J. Moura. Stochastic Optimal Energy Management of Smart Home With PEV Energy Storage, IEEE Transactions on Smart Grid, vol. 9, no. 3, pp. 2065-2075, May 2018.

[3] M. Stecca, L.R. Elizondo, T.B. Soeiro, P. Bauer, P. Palensky, A Comprehensive Review of the Integration of Battery Energy Storage Systems Into Distribution Networks, IEEE Open Journal of the Industrial Electronics Society, vol. 1, pp. 46-65, 2020.

[4] C. Yang, M. Zha, W. Wang, K. Liu, C. Xiang. Efficient energy management strategy for hybrid electric vehicles/plug-in hybrid electric vehicles: review and recent advances under intelligent transportation system, IET Intelligent Transport Systems, vol. 14, no. 7, pp. 702-711, 7 2020.

[5] F. Nadeem, S.M.S. Hussain, P.K. Tiwari, A.K. Goswami, T.S. Ustun. Comparative Review of Energy Storage Systems, Their Roles, and Impacts on Future Power Systems, IEEE Access, vol. 7, pp. 4555-4585, 2019.

[6] X. Chen, X. Zhang. Secure Electricity Trading and Incentive Contract Model for Electric Vehicle Based on Energy Blockchain, IEEE Access, vol. 7, pp. 178763-178778, 2019. 
[7] Modeling, Control, and Integration of Energy Storage Systems in ETransportation and Smart Grid, IEEE Transactions on Industrial Electronics, vol. 65, no. 8, pp. 6548-6551, Aug. 2018.

[8] Opening up new markets for business, Global wind energy council, Technical Report, 2015. Available. [Online]. https://www.gwec.net/wpcontent/uploads/vip/GWEC-Global-Wind-Report_2016.pdf.

[9] PVPS annual report 2016, Technical Report. Available. [Online]. https://iea-pvps.org/wp-content/uploads/2020/01/IEA-PVPS_RA2016web.pdf.

[10] Technology roadmap - wind energy, Technical Report, International Energy Agency, 2013. Available. [Online]: http://www.energienachrichten.info/file/News/2013/2013-10/Wind_2013_Roadmap.pdf.

[11] Technology roadmap - solar photovoltaic energy, Technical Report, Energy Technology Perspectives, 2014 edition, International Energy Agency.

[12] H.F. Gharibeh, A.S. Yazdankhah, M.R. Azizian. Energy management of fuel cell electric vehicles based on working condition identification of energy storage systems, vehicle driving performance, and dynamic power factor, Journal of Energy Storage, vol. 31, Oct. 2020.

[13] D. Li, A. Zouma, J.T. Liao, H.T. Yang. An energy management strategy with renewable energy and energy storage system for a large electric vehicle charging station, eTransportation, vol. 6, Nov. 2020.

[14] R. Machlev, N. Zargari, N.R. Chowdhury, J. Belikov, Y. Levron. A review of optimal control methods for energy storage systems - energy trading, energy balancing and electric vehicles, Journal of Energy Storage, vol. 32, Dec. 2020.

[15] W. Wu, B. Lin, C. Xie, R.J.R. Elliott, J. Radcliffe. Does energy storage provide a profitable second life for electric vehicle batteries?, Energy Economics, vol. 92, Oct. 2020.

[16] H.S. Salama, I. Vokony. Comparison of different electric vehicle integration approaches in presence of photovoltaic and superconducting magnetic energy storage systems, Journal of Cleaner Production, vol. 260, Jul. 2020.

[17] T. Zhu, R. Lot, R.G.A. Wills, X. Yan. Sizing a battery-supercapacitor energy storage system with battery degradation consideration for highperformance electric vehicles, Energy, vol. 208, Oct. 2020.

[18] J. Liu, C. Zhong. An economic evaluation of the coordination between electric vehicle storage and distributed renewable energy, Energy, vol. 186, Nov. 2019.

[19] J. Adamec, M. Danko, M. Taraba, P. Drgona. Analysis of selected energy storage for electric vehicle on the lithium based, Transportation Research Procedia, vol. 40, pp. 127-131, 2019.

[20] N. Vukajlović, D. Milićević, B. Dumnić, B. Popadić. Comparative analysis of the supercapacitor influence on lithium battery cycle life in electric vehicle energy storage, Journal of Energy Storage, vol. 31, Oct. 2020.

[21] M.A. Hannan, M.M. Hoque, A. Mohamed, A. Ayob. Review of energy storage systems for electric vehicle applications: Issues and challenges, Renewable and Sustainable Energy Reviews, vol. 69, pp. 771-789, Mar. 2017.

[22] I.S. Bayram, S. Galloway, G. Burt. A probabilistic capacity planning methodology for plug-in electric vehicle charging lots with on-site energy storage systems, Journal of Energy Storage, vol. 32, Dec. 2020.
[23] J. Hu, D. Liu, C. Du, F. Yan, C. Lv. Intelligent energy management strategy of hybrid energy storage system for electric vehicle based on driving pattern recognition, Energy, vol. 198, May 2020.

[24] S.R. Salkuti, "Electrochemical batteries for smart grid applications", International Journal of Electrical and Computer Engineering (IJECE), vol. 11, no. 3, pp. 1849-1856, Jun. 2021.

[25] S.R. Salkuti, C.M. Jung, "Comparative analysis of storage techniques for a grid with renewable energy sources”, International Journal of Engineering \& Technology, vol. 7, no. 3, pp. 970-976, 2018.

[26] J. Jin, Y. Xu, Z. Yang. Optimal deadline scheduling for electric vehicle charging with energy storage and random supply, Automatica, vol. 11, Sept. 2020.

[27] S.R. Salkuti, C.M. Jung, "Overview of Energy Storage Technologies: A Techno-Economic Comparison", International Journal of Applied Engineering Research, vol. 12, no. 22, pp. 12872-12879, Nov. 2017.

[28] S.R. Salkuti, "Comparative analysis of electrochemical energy storage technologies for smart grid", TELKOMNIKA Telecommunication, Computing, Electronics and Control), vol. 18, no. 4, pp. 2118-2124, Aug. 2020.

[29] T. Yi, X. Cheng, Y. Chen, J. Liu. Joint optimization of charging station and energy storage economic capacity based on the effect of alternative energy storage of electric vehicle, Energy, vol. 208, Oct. 2020.

[30] L. Haupt, M. Schöpf, L. Wederhake, M. Weibelzahl. The influence of electric vehicle charging strategies on the sizing of electrical energy storage systems in charging hub microgrids, Applied Energy, vol. 273, Sept. 2020.

[31] S.R. Salkuti, "Large scale electricity storage technology options for smart grid”, International Journal of Engineering \& Technology, vol. 7, no. 2, pp. 635-639, Apr. 2018.

[32] S.R. Salkuti, "Energy Storage Technologies for Smart Grid: A Comprehensive Review", Majlesi Journal of Electrical Engineering, Vol. 14, No. 1, pp. 39-48, Mar. 2020.

[33] P. Chinnasa, W. Ponhan, W. Choawunklang. Modeling and simulation of a $\mathrm{LaCoO}_{3}$ Nanofibers /CNT electrode for supercapacitor application, Journal of Physics: Conference Series, pp. 1-5, 2019.

[34] M. Khalid. A Review on the Selected Applications of BatterySupercapacitor Hybrid Energy Storage Systems for Microgrids, Energies, vol. 12, no. 23, 2019.

[35] M. Kroupa, G.J. Offer, J. Kosek. Modelling of Supercapacitors: Factors Influencing Performance, Journal of The Electrochemical Society, vol. 163, no. 10, pp. A2475-A2487, 2016.

[36] H.J. Jabir, J. The, D. Ishak, H. Abunima. Impacts of Demand-Side Management on Electrical Power Systems: A Review, Energies, vol. 11, no. 5, 2018.

[37] A. Mohammad, R. Zamora, T.T. Lie. Integration of Electric Vehicles in the Distribution Network: A Review of PV Based Electric Vehicle Modelling, Energies, vol. 13, no. 17, 2020.

[38] C.T. Ma. System Planning of Grid-Connected Electric Vehicle Charging Stations and Key Technologies: A Review, Energies, vol. 12, no. 21, 2019.

[39] A. Simpson. Cost-Benefit Analysis of Plug-In Hybrid Electric Vehicle Technology, National Renewable Energy Laboratory, Conference Paper, NREL/CP-540-40485, Nov. 2006. 